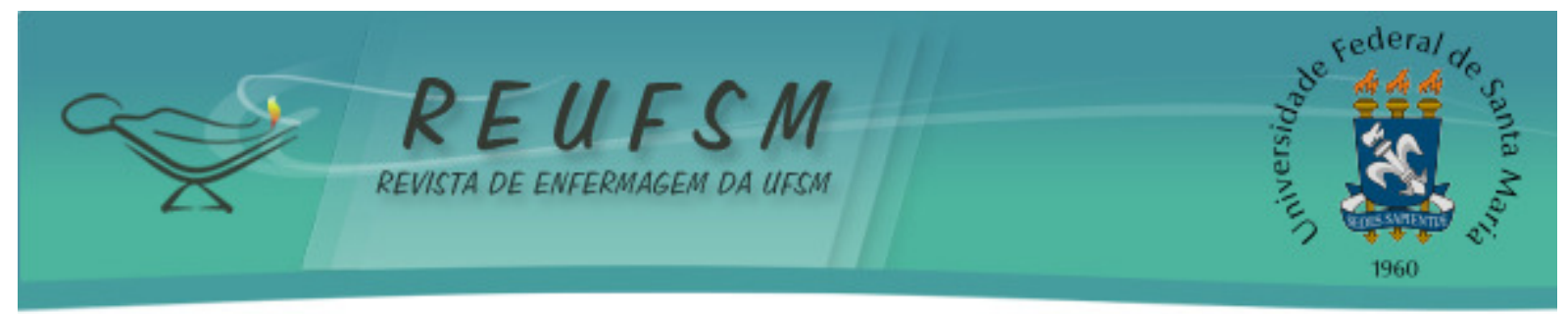

ARTIGO ORIGINAL

\title{
CARACTERIZAÇÃO DOS ACIDENTES DE TRABALHO OCORRIDOS COM TRABALHADORES DE UM HOSPITAL UNIVERSITÁRIO
}

\author{
CHARACTERIZATION ON OF THE ACCIDENTES OCURRED WITH WORKERS IN A \\ UNIVERSITY HOSPITAL
}

\section{CARCTERIZACIÓN DE LOS ACCIDENTES DE TRABALHO OCURRIDOS CON LOS TRABAJADORES DE UN HOSPITAL UNIVERSITARIO}

\author{
Emanuelli Mancio Ferreira da Luz ${ }^{1}$ \\ Tânia Solange Bosi de Souza Magnago ${ }^{2}$ \\ Marinez Diniz da Silva Ceron ${ }^{3}$ \\ Fernando Tolfo ${ }^{4}$ \\ Jéssica Baldissera Carollo
}

RESUMO: Objetivo: caracterizar os acidentes de trabalho ocorridos com trabalhadores de um Hospital Universitário do Rio Grande do Sul. Método: estudo transversal descritivo, cuja coleta ocorreu entre Julho e Setembro de 2012, com base na Notificação de Acidentes de Trabalho (2008-2012). Para a inserção dos dados foi utilizado o programa Epi-info® e a análise dos dados foi realizada no programa PASW Statistics, por meio da estatística descritiva. Resultados: foram avaliadas 252 notificações. Prevaleceram acidentes de trabalho entre trabalhadores do sexo feminino, com idade entre 43 a 66 anos e pertencentes à equipe de enfermagem. Os acidentes ocorreram devido à exposição ao bacilo de Koch e a materiais perfurocortantes. Conclusão: a caracterização dos acidentes permite a elaboração de um diagnóstico, o qual pode ser utilizado pelos gestores em prol da instituição como subsídios para as ações de educação permanente sobre a prevenção dos acidentes de trabalho.

Descritores: Saúde do trabalhador; Acidentes de trabalho; Pessoal de saúde; Epidemiologia descritiva.

ABSTRACT: Aim: to characterize work accidents occurred with workers from the University Hospital of Rio Grande do Sul. Methods: cross-sectional study, which data collection occurred in the period July-September 2012, based on Work accidents Notification (2008-2012). For inserting data, we used Epi-info ${ }^{\circ}$ software and data analysis was developed on PASW Statistics, through descriptive statistics. Results: of the 252 analyzed notifications, there was a prevalence of work accidents among female workers, aged 43 to 66 years old and belonging to the nursing staff. Accidents occurred due to explosion to Koch Bacillus and sharp materials.

\footnotetext{
${ }^{1}$ Enfermeira. Mestranda em Enfermagem pelo Programa de Pós-Graduação em Enfermagem (PPGEnf) da Universidade Federal de Santa Maria (UFSM). Membro do Grupo de Pesquisa Trabalho, Saúde, Educação e Enfermagem do Departamento de Enfermagem da UFSM. E-mail: emanuelli_ferreira@hotmail.com

${ }^{2}$ Doutora em Enfermagem. Professora Adjunta do Departamento e do PPGEnf da Universidade Federal de Santa Maria (UFSM). Líder e Pesquisadora do Grupo de Pesquisa: Trabalho, Saúde, Educação e Enfermagem do Departamento de Enfermagem da UFSM-Linha de Pesquisa Saúde do Trabalhador. E-mail: tmagnago@terra.com.br

${ }^{3}$ Enfermeira. Mestranda em Enfermagem pelo Programa de Pós-Graduação em Enfermagem (PPGEnf) da Universidade Federal de Santa Maria (UFSM). Membro do Grupo de Pesquisa: Trabalho, Saúde, Educação e Enfermagem do Departamento de Enfermagem da UFSM. E-mail: marinezdceron@hotmail.com

${ }^{4}$ Enfermeiro. Mestrando em Enfermagem pelo Programa de Pós-Graduação em Enfermagem (PPGEnf) da Universidade Federal de Santa Maria (UFSM). Membro do Grupo de Pesquisa: Trabalho, Saúde, Educação e Enfermagem do Departamento de Enfermagem da UFSM. E-mail: fernandotolfo@gmail.com

${ }^{5}$ Acadêmica do Curso de Graduação em Enfermagem da Universidade Federal de Santa Maria (UFSM). Membro do Grupo de Pesquisa: Trabalho, Saúde, Educação e Enfermagem do Departamento de Enfermagem da UFSM. Bolsista PROBIC/FAPERGS (2013/2014). E-mail: jeh_bc8@yahoo.com.br
} 


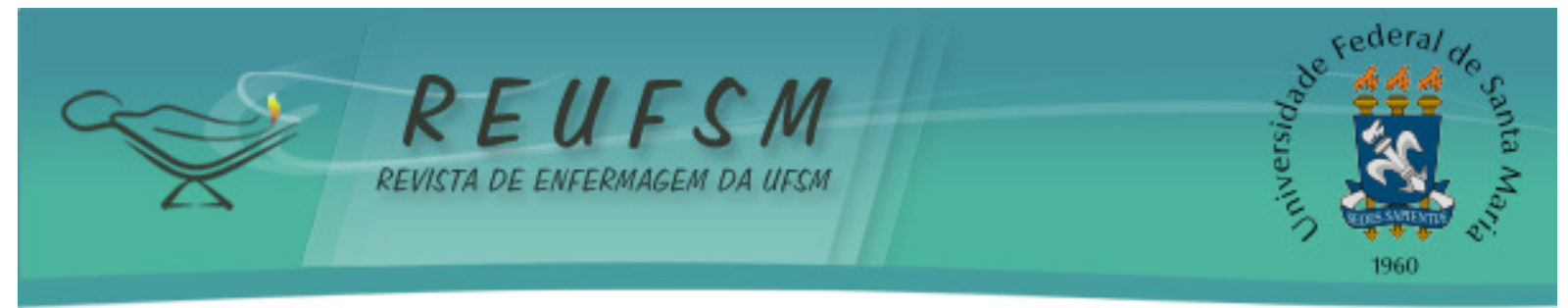

Conclusions: characterization of accidents allows the elaboration of a diagnosis, which can be used by managers on behalf of the institution as subsidies for permanent education actions on the prevention of accidents at work.

Descriptors: Occupational health; Accidents, occupational; Health personnel, Epidemiology descriptive.

RESUMEN: Objetivo: Caracterizar los accidentes de trabajo ocurridos con los empleados de un Hospital Universitario del Rio Grande do Sul. Métodos: estudio transversal descriptivo, cuya la recolección de datos ocurrió entre julio-septiembre 2012, basado en la Notificación de Accidentes de Trabajo (2008-2012). Para la inserción de los datos fue utilizado el programa Epi-Info ${ }^{\circledR}$, y el análisis de datos se realizó con el programa PASW Statistics, mediante el uso de estadística descriptiva. Resultados: Fueron evaluadas 252 notificaciones. Prevalecieron accidentes de trabajo del sexo femenino con edad entre 43-66 años y pertenecientes al personal de enfermería. Los accidentes se produjeron debido a la exposición al bacilo de Koch y a los materiales cortos punzantes. Conclusión: la caracterización de los accidentes permite la elaboración de un diagnóstico, que puede ser utilizado por los administradores en nombre de la institución que favorezca las acciones de educación permanente sobre la prevención de los accidentes de trabajo.

Descriptores: Salud laboral; Accidentes de trabajo; Personal de salud, Epidemiologia descriptiva.

\section{INTRODUÇÃO}

O trabalho pode ser percebido como fonte de felicidade e prazer, evidenciado pelo progresso pessoal e econômico proporcionado aos indivíduos e também como causador de sofrimentos, desgastes físicos e/ou psíquicos, doenças ocupacionais e acidentes de trabalho (AT). ${ }^{1}$

No Brasil, de acordo com dados estatísticos da Previdência Social, em 2011, foram registrados 730.585 acidentes e doenças do trabalho entre os profissionais assegurados da Previdência Social, tendo como consequência o afastamento do trabalhador de seu ambiente laboral. ${ }^{2}$ No Rio Grande do Sul, nesse mesmo ano, foram registrados no Sistema de Informação sobre Saúde do Trabalhador (SIST/RS), 58.887 agravos. Desses, 1,219 causaram incapacidade permanente, 49.840 geraram incapacidade temporária e 171 causaram óbito. ${ }^{2}$

No ambiente hospitalar, os trabalhadores manuseiam materiais potencialmente infectantes, sendo que a exposição ocupacional pode resultar em AT, o qual é definido como todo incidente que ocorre durante o exercício da profissão, capaz de provocar lesões ou alterações corporais que possam levar à morte, à perda ou à diminuição passageira ou definitiva da produtividade do trabalhador. ${ }^{3}$ Dentre os AT, há o acidente típico, que ocorre durante o desempenho das atividades laborais e o AT de trajeto, que ocorre durante o deslocamento entre a residência e o local de trabalho do profissional. ${ }^{3}$

Embora a exposição dos trabalhadores aos riscos ocupacionais seja motivo de preocupação e uma realidade discutida nas últimas décadas, ainda há a subnotificação dos dados. ${ }^{4-5}$ Com base no conhecimento sobre os fatores que interferem na ocorrência dos AT em ambiente hospitalar, torna-se possível identificar as razões pelas quais ocorrem esses AT, bem como os fatores preventivos desses agravos. ${ }^{5}$ Tendo em vista essa problemática, têm-se como questão norteadora: Quais são as características dos AT ocorridos com os trabalhadores de um Hospital Universitário do Rio Grande do Sul? Sob essa perspectiva, traça-se como objetivo caracterizar os AT de um Hospital Universitário do Rio Grande do Sul. 


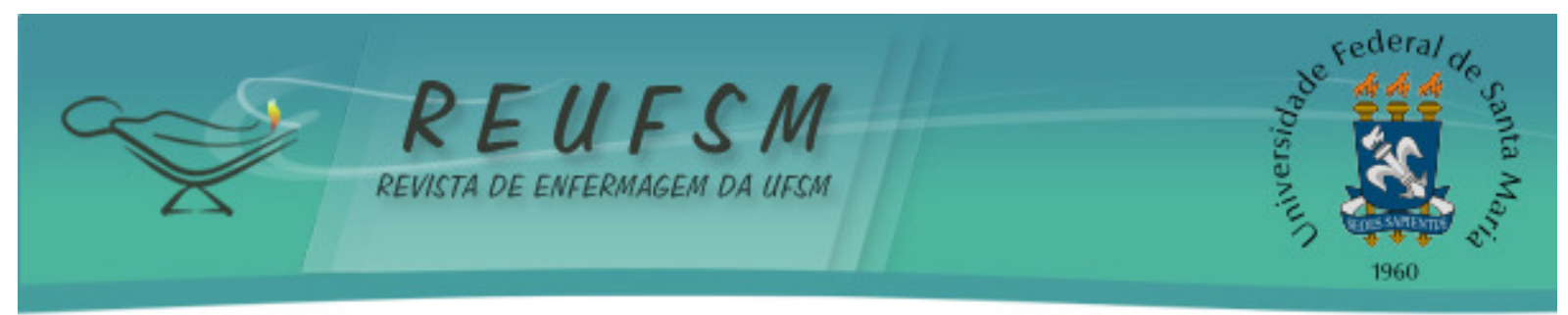

MÉTODO

Trata-se de um estudo transversal descritivo com análise documental e abordagem quantitativa, realizada junto ao Serviço de Saúde e Segurança do Trabalhador (SSST) de um Hospital Universitário do Rio Grande do Sul, por meio da análise dos formulários utilizados para registrar os AT, denominados Notificação de Acidentes de Trabalho (NAT).

0 estudo utilizou a NAT, por esta ser o meio de registro dos AT no Hospital supracitado. No Brasil, o Ministério da Previdência Social preconiza a utilização da Comunicação de Acidente de Trabalho (CAT) como o formulário de registro. No entanto, salienta-se que ela pode ser substituída por outro formulário impresso pela própria instituição, como é o caso da NAT, desde que esta possua sistema de informação de pessoal com processamento eletrônico e que contenha todas as informações exigidas pelo INSS. ${ }^{6}$

A coleta de dados foi realizada no SSST, no período de julho a setembro de 2012, por acadêmicos de enfermagem previamente capacitados pela pesquisadora responsável. Foram obtidas 252 NAT preenchidas no período de janeiro de 2008 a janeiro de 2012. 0 recorte temporal justifica-se pelo fato da inexistência de registros arquivados no referido setor, anterior a esse período.

Para a coleta de dados, foi elaborado um formulário próprio pelos autores, com base na ficha de NAT, contemplando dados sociodemográficos (sexo, idade), laborais (profissão, unidade na qual desempenha suas atividades, turno de trabalho) e questões relacionadas ao acidente (tipo de acidente, agente causador da lesão, partes do corpo atingidas, hora do acidente e condutas tomadas após a ocorrência do acidente).

Para a inserção dos dados, foi utilizado o programa Epi-info®, versão 6.4, com dupla digitação independente. Após a verificação de erros e inconsistências, a análise dos dados foi realizada no programa PASW Statistics ${ }^{\circledR}$ (Predictive Analytics Software, da SPSS Inc., Chicago - USA) 18.0 for windows. Utilizou-se a estatística descritiva (média, mediana, desvio padrão para as variáveis quantitativas; frequências absolutas $(N)$ e percentuais $(\%)$ para as variáveis qualitativas).

Quanto às questões éticas envolvidas nesse tipo de pesquisa, o projeto recebeu parecer favorável do Comitê de Ética em Pesquisa de uma Universidade do Rio Grande do Sul, sob a CAAE $n^{\circ}$ 05206912.1.0000.5346. Ademais, a privacidade dos dados foi preservada por meio da assinatura do Termo de Confidencialidade.

\section{RESULTADOS E DISCUSSÃO}

No período avaliado foram notificados 252 AT com os trabalhadores do hospital pesquisado. Destes, $96 \%$ foram classificados como acidentes típicos e $4 \%$ como acidentes de trajeto (em rodovias devido a colisões de veículo no transporte de paciente, em ambulâncias nas transferências para outros hospitais, bem como na volta do trabalhador para casa).

Observa-se maior percentual de notificações de AT no ano de 2009 (38,1\%), seguido pelo ano de 2008 (25\%), 2011 (22,2\%) e 2010 (14,3\%). Verifica-se que 82,1\% (N=207) dos profissionais acidentados são do sexo feminino. Isso se deve ao fato de que a enfermagem foi a categoria profissional mais acometida pelos AT $(77,3 \%)$. Historicamente, a enfermagem é composta, majoritariamente, pela população feminina ${ }^{7}$, além de ser a força de trabalho predominante nas instituições de saúde.

Com relação à idade, o maior percentual de AT foi evidenciado com trabalhadores entre 43 e 66 anos (39,5\%). A média de idade foi 39,3 anos $( \pm 9,96)$, mínimo 20 e máximo de 66 anos. A idade em que o AT mais se repetiu foi 33 anos. Destaca-se que em 19 NATs (7,5\%), essa informação não estava presente.

Na Tabela 1, apresenta-se a profissão dos trabalhadores acidentados. 


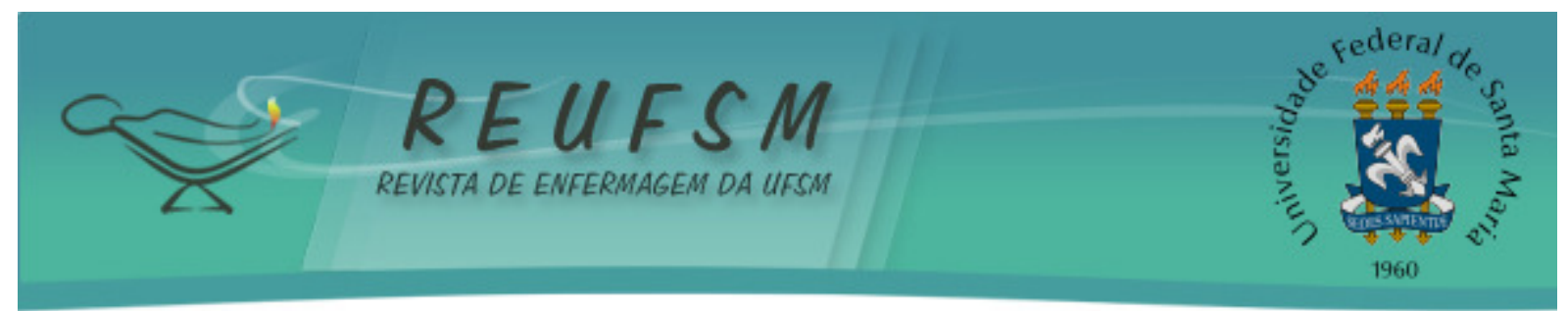

Tabela 1 - Distribuição dos trabalhadores acidentados no Hospital pesquisado, no período de 2008 a 2011, segundo profissão. Santa Maria, RS, 2012. ( $\mathrm{N}=252)$

\begin{tabular}{lrr}
\hline CARGO (profissão) & N & $\%$ \\
\hline Equipe de Enfermagem (técnicos, auxiliares de enfermagem e enfermeiros) & 195 & 77,4 \\
Auxiliar de laboratório; Laboratorista, Técnico de laboratório. & 14 & 5,5 \\
Acadêmicos/ estagiários de diversos cursos da área da saúde & 13 & 5,1 \\
Dado deixado em branco & 8 & 3,1 \\
Médicos e Residentes Médicos & 5 & 1,9 \\
Profissionais que não pertencem a área da saúde (marceneiro, motorista de & 6 & 2,3 \\
ambulância, copeira, servente de limpeza) & & \\
Auxiliar de saúde & 3 & 1,1 \\
Fisioterapeuta & 3 & 1,1 \\
Instrumentador & 2 & 0,8 \\
Técnico em Radiologia & 2 & 0,8 \\
Nutricionista & 1 & 0,3 \\
\hline Total & 252 & 100 \\
\hline
\end{tabular}

Cabe destacar que, no que se refere aos AT com a equipe de enfermagem, $76,4 \%$ $(\mathrm{N}=149)$ ocorreram com os técnicos e auxiliares de enfermagem. No processo de trabalho da enfermagem eles são os mais envolvidos em AT com material perfurocortante. Estudo ${ }^{8}$ aponta que os motivos podem estar relacionados ao tipo e quantidade de atividades desenvolvidas por essa categoria profissional. Dentre as atividades, pode-se citar: ${ }^{9}$ administração de medicamentos, incluindo os injetáveis, punções venosas, realização de curativos, aspiração de secreção traqueal, e outros procedimentos que os mantêm em constante risco de acidente.

Também se observa (Tabela 1) que os acadêmicos da área da saúde compuseram a terceira categoria que mais se acidentou. Diante disso, ressalta-se que os acidentes ocupacionais envolvendo os mesmos não são computados por estatísticas oficiais e que esta situação não prevê a emissão da CAT. Todavia, a cobertura de assistência à saúde para os estudantes depende da instituição a qual eles pertencem. ${ }^{10}$ No caso do Hospital dessa pesquisa, o acadêmico está incluído na cobertura de seguro contra acidentes pessoais, que visa a cobertura de eventos que, porventura, possam ocorrer durante o estágio curricular e extra-curricular. Com isso, nessa instituição, há a notificação dos AT com acadêmicos, o que contribui tanto para a redução das subnotificações dos mesmos, como para a instituição de medidas de educação em saúde.

Neste contexto, os acidentes com acadêmicos $(\mathrm{N}=13 ; 5,1 \%)$, aconteceram devido à lesão por material perfurocortante $(61,5 \%)$. Para os acadêmicos, o manuseio de material perfurocortante é considerado um desafio, visto que ainda se encontram em desenvolvimento das habilidades, sendo comum o nervosismo, a falta de destreza manual e a ansiedade para realizar os procedimentos. ${ }^{10} 0$ desenvolvimento de atividades em laboratório de práticas de enfermagem é recomendado, tendo em vista que contribui para melhorar a destreza manual, dar maior segurança na execução do procedimento e maior familiarização com os materiais (manuseio e descarte).

Quanto ao local em que ocorreram os AT, observa-se maior percentual no Centro de Tratamento Intensivo (CTI) adulto (36,5\%), seguido pela Clínica Médica (15,1\%), Pronto 


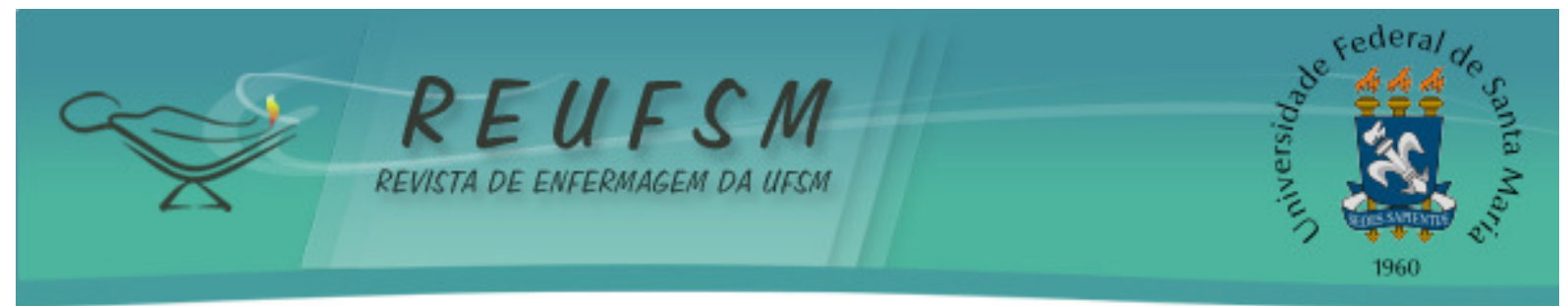

Socorro Adulto (PS Adulto) (4,8\%), Nefrologia (4,8\%) e Centro Cirúrgico (4\%). Destaca-se que 6,3\% ( $\mathrm{N=16})$ dos AT ocorreram fora das enfermarias, ou seja, aconteceram na calçada, corredor, elevador, escada ou pátio do hospital.

O CTI adulto é considerado uma unidade com alto grau de dependência de assistência direta aos pacientes por parte da equipe, em especial da enfermagem. ${ }^{11}$ Nessa unidade, são prestadas inúmeras intervenções com manuseio constante de material biológico e perfurocortantes, fatores que aumentam o risco de AT. ${ }^{12}$

Quanto ao turno de trabalho de maior ocorrência dos AT, destaca-se o turno da manhã $(24,2 \%, N=61)$. Todavia, ressalta-se que este item não foi preenchido em $46,4 \%$ $(\mathrm{N}=117)$ das NAT. Corroborando a isso, estudo anterior comprova a maior ocorrência de AT no período diurno e, dentre as possíveis causas estão: maior concentração de funcionários e de atividades, como a administração de medicações, realização de curativos e ritmo acelerado de trabalho. ${ }^{13}$

A distribuição do horário de ocorrência dos acidentes está descrita na Tabela 2.

Tabela 2 - Distribuição dos trabalhadores acidentados no Hospital pesquisado, no período de 2008 a 2011, segundo horário do acidente. Santa Maria, RS, 2012. ( $N=252$ )

\begin{tabular}{|c|c|c|}
\hline Hora do acidente & $\mathbf{N}$ & $\%$ \\
\hline $07: 00$ às $07: 59$ & 12 & 4,8 \\
\hline $08: 00$ às $08: 59$ & 10 & 4,0 \\
\hline 09:00 às 09:59 & 05 & 2,0 \\
\hline $10: 00$ às $10: 59$ & 13 & 5,2 \\
\hline $11: 00$ às $11: 59$ & 12 & 4,8 \\
\hline $12: 00$ às $12: 59$ & 09 & 3,6 \\
\hline SubTotal turno manhã & 61 & 24,4 \\
\hline $13: 00$ às $13: 59$ & 10 & 4,0 \\
\hline $14: 00$ às $14: 59$ & 06 & 2,4 \\
\hline $15: 00$ às $15: 59$ & 10 & 4 \\
\hline $16: 00$ às $16: 59$ & 05 & 2,0 \\
\hline $17: 00$ às $17: 59$ & 05 & 2,0 \\
\hline $18: 00$ às $18: 59$ & 09 & 3,6 \\
\hline SubTotal turno Tarde & 45 & 18,0 \\
\hline $19: 00$ às $19: 59$ & 04 & 1,6 \\
\hline 20:00 às 20:59 & 06 & 2,4 \\
\hline $21: 00$ às $21: 59$ & 01 & 0,4 \\
\hline $22: 00$ às $22: 59$ & 05 & 2,0 \\
\hline $23: 00$ às $23: 59$ & 04 & 1,6 \\
\hline $00: 00$ às $00: 59$ & 1 & 0,4 \\
\hline $01: 00$ às $01: 59$ & -- & -- \\
\hline $02: 00$ às $02: 59$ & 1 & 0,4 \\
\hline 03:00 às 03:59 & -- & -- \\
\hline $04: 00$ às $04: 59$ & 1 & 0,4 \\
\hline 05:00 às 05:59 & 2 & 0,8 \\
\hline $06: 00$ às $06: 59$ & 4 & 1,6 \\
\hline SubTotal turno noturno & 29 & 11,6 \\
\hline Dado em branco & 117 & 46,4 \\
\hline Total & 252 & 100,0 \\
\hline
\end{tabular}

Na Tabela 2, observa-se que o início e o final dos turnos são os momentos em que há maior ocorrência. Destaca-se que no turno da manhã os percentuais praticamente se mantêm e, no turno da tarde, observa-se um pico de AT no meio da tarde. Essas evidências 


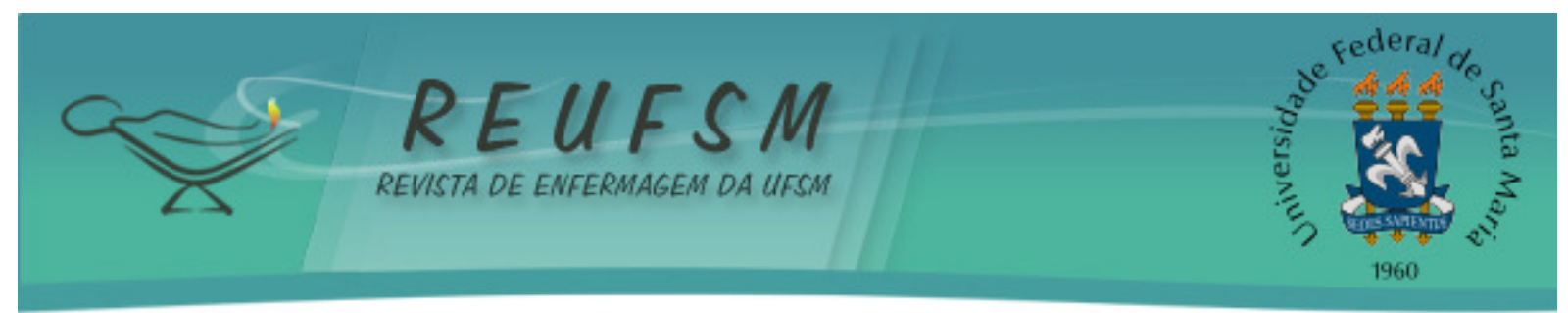

vão ao encontro da dinâmica laboral no ambiente hospitalar, em que há uma concentração de atividades no início e final de cada turno. Sinaliza, ainda, para que os gestores atentem para o quantitativo de pessoal no turno da manhã tendo em vista que a maior concentração de atividades e o ritmo acelerado podem não estar em acordo com o numérico de pessoal para desenvolver as atividades, resultando em AT.

Com relação ao número de horas trabalhadas, observou-se que 36,9\% ( $\mathrm{N}=93$ ) dos acidentes ocorreram em até 5 horas trabalhadas e 7,5\% ( $\mathrm{N}=19)$ após 5 horas. Todavia, $55,6 \%(N=140)$ das NAT, encontravam-se em branco nesse item, o que evidencia o notável percentual de subnotificação dos dados preconizados na NAT.

Quanto ao agente causador, 50,8\% dos AT ocorreram devido à exposição ao Bacilo de Kock e $23,4 \%$ por manuseio de material perfurocortante, que incluem, em ordem decrescente: agulha $(16,3 \%)$, mandril de punção venosa $(2,8 \%)$, lâmina de bisturi $(1,9 \%)$, abocath $(1,2 \%)$, tesoura $(0,8 \%)$ e ponta de equipo $(0,4 \%)$. 0 ato de quebrar a ampola do medicamento foi causador de AT em $0,8 \%$ das NAT analisadas.

Os demais AT foram causados, em ordem decrescente, por quedas (11\%); manuseio de secreção traqueal durante aspiração traqueal $(3,8 \%)$; contato direto com sangue (3\%); manuseio de paciente ocasionando agressão física por parte dos mesmos (2\%) e manuseio de urina e quimioterápicos $(0,8 \%$ cada). Obteve-se AT causados por acidentes de trânsito, na transferência de pacientes para outros hospitais $(2,4 \%)$, bem como AT causados por picada de abelha no interior do hospital $(0,4 \%)$, exposição a líquido de toracocentese $(0,4 \%)$, trauma em telefone público $(0,4 \%)$ e em porta de elevador $(0,4 \%)$. Em $0,4 \%$ das NAT esse item estava em branco.

No que se refere aos AT causados por exposição ao Bacilo de Koch, esses se devem a notificações de prestação de assistência a pacientes com tuberculose, cujo diagnóstico só foi realizado após alguns dias de internação. Esses pacientes foram atendidos no PS Adulto e no CTI Adulto, sendo que os profissionais de saúde talvez tenham realizado a assistência direta a eles sem o uso do EPI adequado, a máscara N95. A notificação dessa exposição foi realizada após ter sido confirmado o diagnóstico. Destaca-se ainda que, no período de avaliação compreendida por este estudo, não houve nenhuma notificação de tuberculose com esses trabalhadores.

Com relação a esse tipo de exposição, os trabalhadores da área da saúde, ao desempenharem as suas atividades laborais, encontram-se expostos aos riscos ocupacionais, denominados riscos biológicos. ${ }^{14}$ Estes riscos, de acordo com a NR 09, são decorrentes do contato com as bactérias, fungos, bacilos, parasitas, protozoários, vírus, entre outros. ${ }^{15}$ Por esse motivo, é importante o levantamento criterioso da história de saúde do paciente, dos sinais e sintomas e que a hipótese diagnóstica seja comunicada o mais rapidamente possível à equipe, a fim de que as medidas de proteção sejam adotadas.

Os acidentes com materiais perfurocortantes foram a segunda causa de AT neste estudo $(23,4 \%)$. Por isso, eles devem ser considerados por representarem gravidade especial, devido à possibilidade de contaminação biológica. ${ }^{16}$ Neste estudo, foi observado nas descrições dos AT, alguns fatores predisponentes à ocorrência dos acidentes, tais como: o ato de reencape de perfurocortantes (após a realização do Hemoglucoteste (HGT) e após a coleta de sangue), o acondicionamento inadequado dos materiais (agulha solta sobre os lençóis dos pacientes, na janela da enfermaria) e no ato de desprezar os perfurocortantes no coletor para material perfurocortante. Destaca-se que desprezar os perfurocortantes nesse coletor é considerado como um ato seguro, porém em situações nas quais o limite de resíduos for ultrapassado e quando o acondicionamento do recipiente for inadequado $o$ trabalhador poderá acidentar-se no momento de desprezar o perfurocortantes. 


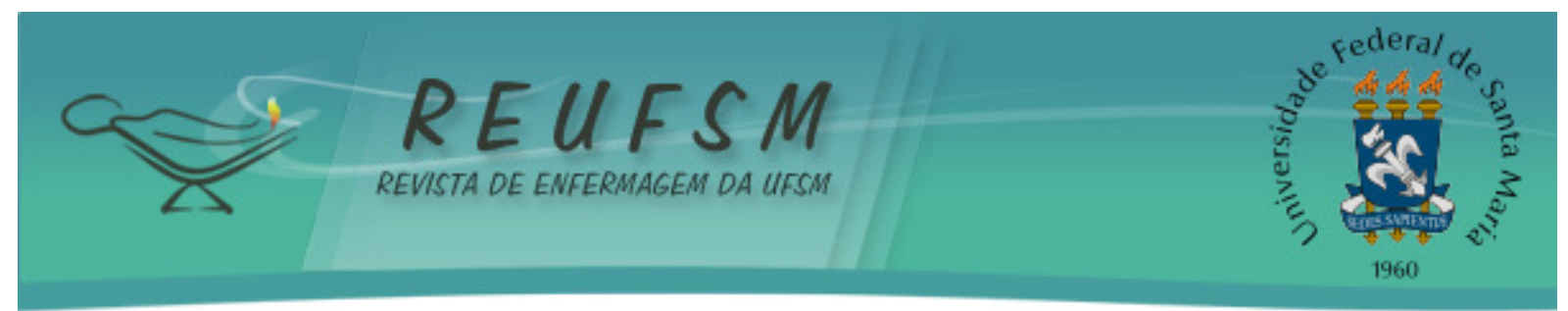

Com relação ao ato de reencape de perfurocortantes, embora o Centers for Disease Control and Prevention (CDC) não recomende essa prática, ela ainda permanece no cotidiano dos hospitais. Em uma pesquisa ${ }^{10}$, constatou-se que essa prática é considerada aceitável pela possível falsa impressão de favorecer a redução do risco de AT, sendo que $73,2 \%$ dos pesquisados reencapam as agulhas, com intensidades variadas.

Como terceira causa dos AT, obteve-se as quedas (11\%), sendo as mesmas ocorridas em cadeiras, ao atravessar a rua em frente ao Hospital, ao puxar carrinho de autoclave, deslize em calçamentos irregulares, em escadas no interior do Hospital e após tropeço em fios do monitor cardíaco.

Foram descritos 3,8\% de AT causados por secreção traqueal do paciente, no ato da aspiração de traqueostomia e tubo oro-traqueal. Assim, para minimizar o risco de AT e transmissão ocupacional de material biológico, as sociedades internacionais instituíram as recomendações para adoção das precauções-padrão. ${ }^{17}$ Estas precauções são baseadas nas seguintes medidas: higienização das mãos, uso de Equipamento de Proteção Individual (EPI), manuseio e descarte adequado de materiais perfurocortantes e a imunização dos profissionais para hepatite B. No ano de 2007, foram acrescentadas recomendações de boas práticas para aplicação de medicamentos injetáveis, etiqueta respiratória, reprocessamento de produtos para saúde e cuidados com ambientes e superfícies. ${ }^{18}$

Para a redução da exposição a esses riscos, a Norma Regulamentadora 6 (NR 6) dispõe sobre os EPIs, como todo dispositivo ou produto, de uso individual utilizado pelo trabalhador, destinado à proteção contra riscos suscetíveis de ameaçar a segurança e a saúde no trabalho. ${ }^{19}$ São considerados como EPI's a máscara facial, óculos de proteção, avental e luvas de procedimento. Ressalta-se que o risco de infecção pelo HIV pósexposição percutânea com sangue contaminado é de aproximadamente $0,3 \%$ e de $0,09 \%$ por exposição de mucosas. No caso das hepatites os percentuais variam de $33 \%$ para transmissão da hepatite $\mathrm{B}$ e $3 \%$ para hepatite $\mathrm{C} .{ }^{17}$

Todavia, no que se refere ao uso dos EPIs pelos profissionais, na hora da ocorrência do AT, não foi possível a obtenção desse dado na NAT, sendo uma falha no documento.

No que tange aos AT causados por agressão física (2\%), evidenciou-se que elas ocorreram durante 0 procedimento de contenção mecânica de pacientes agitados e agressivos. A agressão foi derivada de socos e pontapés, que geraram lesões, como: dores musculares, hematomas e rupturas de tendão.

A parte do corpo atingida no acidente está apresentada na Tabela 3.

Tabela 3 - Distribuição dos trabalhadores acidentados, segundo parte do corpo atingida pelo acidente. Santa Maria, RS, 2012. ( $\mathrm{N}=252)$

\begin{tabular}{lll}
\hline PARTE DO CORPO ATINGIDA & N & $\%$ \\
\hline Cabeça/pescoço & 21 & 8,3 \\
Membros superiores & 69 & 27,4 \\
Via respiratória & 128 & 50,8 \\
Tórax & 3 & 1,2 \\
Abdome/dorso & 4 & 1,6 \\
Membros inferiores & 16 & 6,3 \\
Item: “Não se aplica” & 1 & 0,4 \\
Dados em branco & 10 & 4,0 \\
\hline TOTAL & 252 & 100 \\
\hline
\end{tabular}




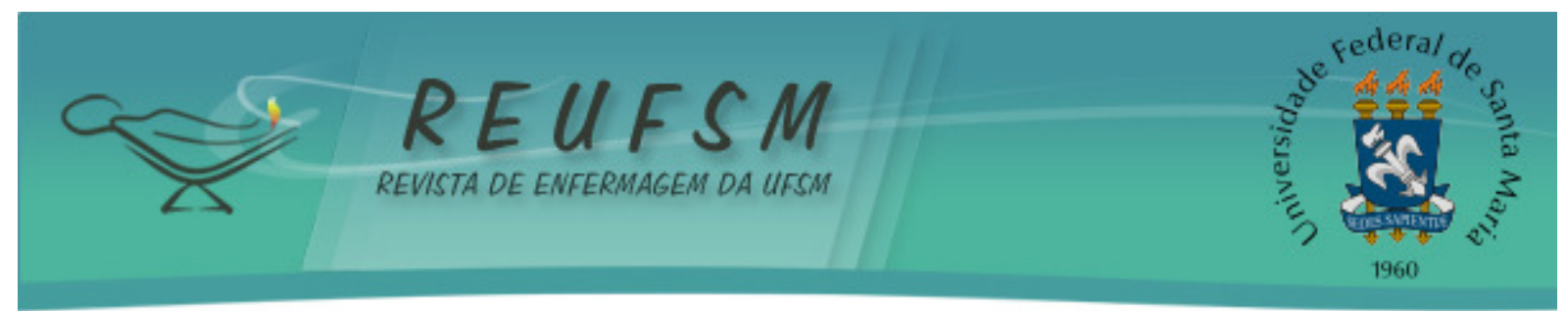

$\mathrm{Na}$ Tabela 3, observa-se que a via respiratória foi a parte do corpo mais atingida devido a exposição ao Bacilo de Koch. Após, encontra-se as lesões em membros superiores que, quando ocorridas em trabalhadores da saúde, justifica-se por, em sua maioria, os procedimentos de risco realizados envolverem as mãos e braços. ${ }^{13}$

Os tipos de materiais que os trabalhadores entraram em contato durante os AT estão descritos na Tabela 4.

Tabela 4 - Distribuição dos trabalhadores acidentados, segundo tipo de material a que foi exposto no acidente. Santa Maria, RS, 2012. ( $N=252)$

\begin{tabular}{lrr}
\hline Tipo de material & $\mathrm{N}$ & $\%$ \\
\hline Secreção/aerosol & $\mathbf{1 3 6}$ & $\mathbf{5 4}$ \\
Sangue & 58 & 23 \\
Não se aplica/outro & 49 & 19,5 \\
Em branco & 09 & 3,6 \\
\hline Total & 252 & 100,0 \\
\hline
\end{tabular}

No que se refere ao paciente-fonte e sua situação sorológica, evidenciou-se diagnóstico de HIV positivo em 4,8\% dos casos, hepatite $\mathrm{C}$ em $2,4 \%$ e com associação de HIV positivo e Hepatite $C$, em $2,8 \%$. No entanto, a situação sorológica dos pacientes não foi informada em $54,36 \%$ das NAT analisadas neste estudo. Outro estudo ${ }^{20}$ evidenciou percentual de $44,9 \%$ de situação sorológica desconhecida do paciente-fonte em acidentes causados por agulhas.

Já com relação à situação sorológica do trabalhador acidentado, ressalta-se que em $17,5 \%$ possuíam sorologias prévias negativas para Hepatite C, HIV e Hepatite B, pois em $35,7 \%$ a situação era desconhecida, em $36,1 \%$ esse item estava em branco e em 10,7\% das NAT analisadas foi marcada a opção "esse item não se aplica”. Quanto à profilaxia utilizada pelos trabalhadores acidentados que tiveram contato com sangue, secreção e outro tipo de material, em 4,4\% dos AT foi necessário a profilaxia medicamentosa e $22,4 \%$ não precisaram de nenhuma medida profilática. Todavia, em 62,1\% dos casos a opção estava em branco.

Assim, após a ocorrência de um acidente, condutas podem prevenir infecções e devem ser adotadas, incluindo a avaliação imediata do acidentado, quimioprofilaxia quando necessária, aconselhamento e o acompanhamento periódico do acidentado. ${ }^{20-21}$ Contudo, embora a conduta da quimioprofilaxia reduza o risco de infecção aos vírus da imunodeficiência humana (HIV) e da hepatite B (HBV) após a exposição ocupacional, ela não traz benefícios para o vírus da hepatite $\mathrm{C}(\mathrm{HCV}) .{ }^{20}$

Para reduzir o risco de exposição aos AT, medidas de proteção individual, como os Equipamentos de Proteção Individual (EPI) e coletiva são fundamentais e a prevenção é a melhor medida para evitar a transmissão ocupacional. ${ }^{22}$ Todavia, apesar de obrigatórios, os EPI nem sempre estão disponíveis nos serviços de saúde, o que constitui um fator determinante para a adoção dos mesmos por parte dos trabalhadores e compromete a realização de suas funções com segurança. ${ }^{23}$

Sobre a conduta tomada após a ocorrência do AT, destaca-se o fato de que em $50,8 \%$ das NAT essa opção foi deixada em branco, 44,4\% tiveram como conduta a aceitação do ocorrido e $4,8 \%$ buscaram contato com a chefia. Estudos anteriores comprovam que a opção por não realizar nenhuma conduta após a ocorrência do AT pode ser atribuída a diversas razões, como o conhecimento da sorologia do paciente-fonte e a certeza que o paciente não é portador de doenças transmissíveis, a pouca importância atribuída ao acidente e ao pequeno volume de material biológico envolvido. ${ }^{10}$

Ao ser avaliada a necessidade de afastamento do trabalho em decorrência do AT, quatro profissionais necessitaram de afastamento. Não foi possível identificar na NAT o 


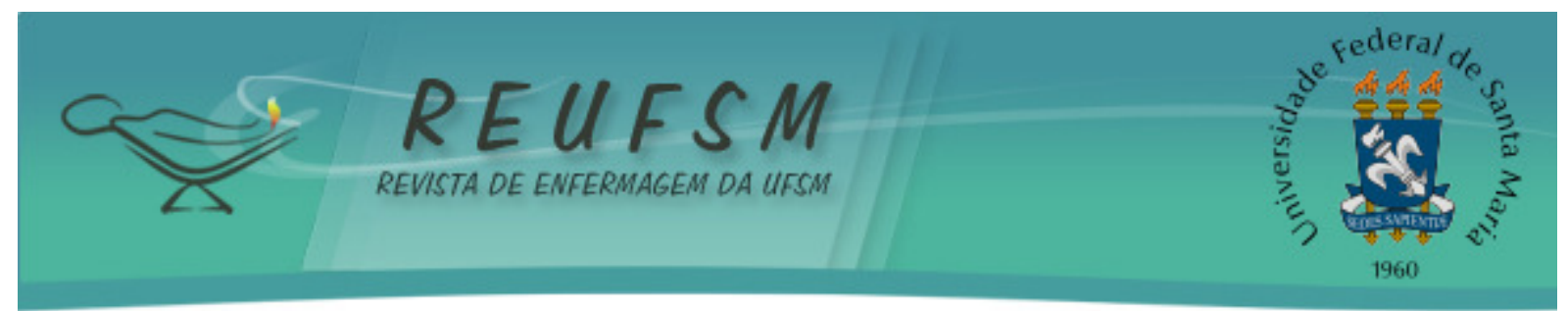

período desse afastamento, pois 142 deixaram essa opção em branco na NAT. Com relação ao preenchimento do formulário (CAT ou NAT), recomenda-se que não seja deixado nenhum item em branco, nem sejam feitas emendas ou rasuras. ${ }^{6}$ Embora a exposição dos trabalhadores aos riscos ocupacionais seja uma realidade discutida nas últimas décadas, ainda há a subnotificação dos dados. ${ }^{4}$ Verificou-se, neste estudo, percentuais de até $62,1 \%$ de itens deixados em branco, como no item tipo de profilaxia utilizada.

A constatação de alto percentual de subnotificação dos dados nas NATs podem sinalizar para uma banalização dos riscos que os AT podem causar. Com isso, evidencia-se a necessidade de capacitação dos profissionais da saúde para o correto preenchimento do formulário e a importância do registro das informações completas. Em decorrência dessa subnotificação, medidas epidemiológicas, bem como a implementação de ações de prevenção e promoção a saúde do trabalhador, podem estar sendo negligenciadas, o que não aconteceria se os verdadeiros resultados fossem evidenciados. ${ }^{5}$

\section{CONCLUSÃO}

0 presente estudo identificou a notificação de 252 AT num período de cinco anos, sendo $96 \%$ acidentes típicos e $4 \%$ de trajeto. As características dos AT que prevaleceram foram: entre trabalhadores do sexo feminino, com idade entre 43 a 66 anos, pertencentes à equipe de enfermagem, do Centro de Terapia Intensiva e do turno da manhã. Maior percentual dos acidentes ocorreu no início ou final do turno, com até cinco horas trabalhadas. Destacaram-se à exposição ao Bacilo de Kock e os acidentes com perfurocortantes.

Considerando-se o percentual de AT por exposição ao Bacilo de Koch, destaca-se a importância tanto da agilização do diagnóstico médico, quanto da comunicação aos demais profissionais sobre o provável diagnóstico de tuberculose, afim de que a equipe multiprofissional possa tomar as medidas de proteção adequadas.

A equipe de enfermagem foi a categoria que apresentou o maior percentual de AT. Nesse sentido, a fim de diminuir a exposição aos AT por parte da equipe de enfermagem, o enfermeiro, como gerente da equipe, possui papel fundamental em ações de educação permanente em saúde de forma a capacitar os profissionais sobre as formas de prevenção dos AT, tanto na utilização das medidas de precaução padrão ao prestarem assistência aos pacientes, quanto no descarte correto de materiais perfurocortantes. Destaca-se a importância da estruturação e atuação do serviço de atenção à saúde do trabalhador em ambiente hospitalar, que poderá implementar e manter ações permanentes de educação e atualização sobre a prevenção dos AT.

Diante da realidade identificada de subnotificação de dados nas NATs, sugere-se que as instituições promovam capacitações aos profissionais sobre a importância do preenchimento correto do formulário de notificação, tendo em vista que as informações nele contidas são de grande valia para a análise dos acidentes, não apenas do ponto de vista previdenciário, estatístico e epidemiológico, mas também trabalhista e social. Com o correto preenchimento dos formulários de notificação, será possível a elaboração de medidas preventivas eficazes, com base nos verdadeiros resultados dos AT.

Espera-se que este estudo contribua para o aumento da informação sobre os AT e, consequentemente, a diminuição da subnotificação dos mesmos. Além disso, auxilie para a reflexão sobre a prática profissional, a fim de possibilitar a revisão de estratégias de promoção da saúde dos trabalhadores para minimizar o risco da ocorrência de acidentes, sensibilizando os profissionais e pesquisadores quanto à importância da notificação correta dos acidentes junto aos serviços competentes. 


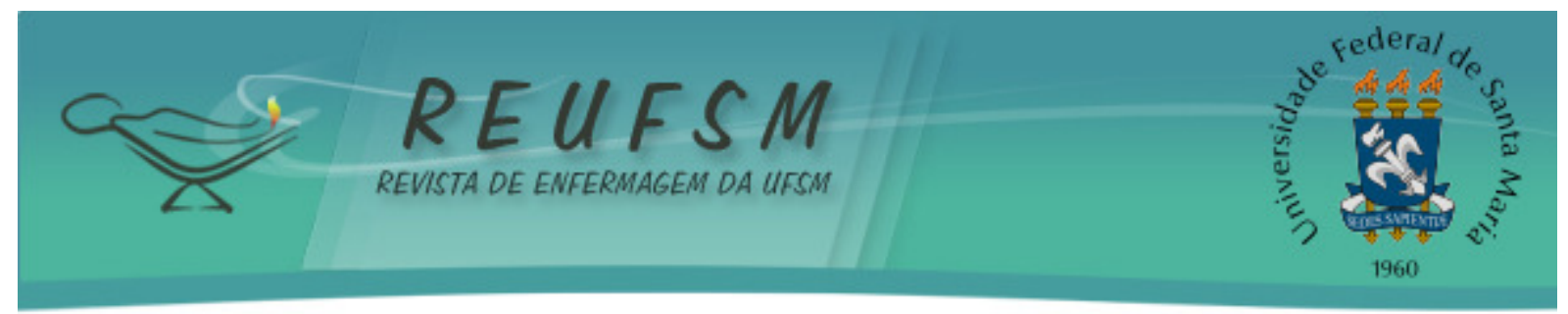

\section{REFERÊNCIAS}

1. Beck CLC, Prestes FC, Tavares JP, Silva RM, Prochonow AG, Nonnenmacher CQ. Identidade profissional dos enfermeiros de serviços de saúde municipal. Cogitare Enferm [Internet]. 2009 [acesso em 2012 set 3];14(1):114-9. Disponível em: http://ojs.c3sl.ufpr.br/ojs2/index.php/cogitare/article/viewArticle/14140.

2. Brasil. Ministério da Previdência Social. Anuário estatístico da Previdência Social 2011. Brasília [Internet]. 2012 [acesso em 2012 set 8]. Disponível em: http://www.mpas.gov.br.

3. Brasil. Ministério do Trabalho e Emprego. Legislação. Norma Regulamentadora 6 (NR 6). Brasília: Ministério da saúde [Internet]. 2011 [acesso em 2012 set 10]. Disponível em: http://portal.mte.gov.br/legislacao/normas-regulamentadoras-1.htm.

4. Kirchhof ALC, Magnago TS, Urbanetto JS, Cera MC, Marques CS, Capellari C. Os acidentes de trabalho atendidos em pronto atendimento de hospital universitário. Esc Anna Nery Rev Enferm [Internet]. 2003 [acesso em 2012 ago 10];7(3):361-8. Disponível em: http: / / www.redalyc.org/articulo.oa?id=127718223008.

5. Santana VS, Nobre L, Waldvogel B. Acidentes de trabalho no Brasil entre 1994 e 2004: uma revisão. Ciênc Saúde Coletiva [Internet]. 2005 [acesso em 2012 out 2];10(4):841-55. Disponível em: http://www.scielo.br/scielo.php?script=sci_arttext\&pid=S1413$81232005000400009 \& \operatorname{lng}=$ en\&nrm=iso\&tlng=pt.

6. Brasil. Ministério da Previdência Social. Instituto Nacional do Seguro Social. Previdência Social. Manual de instruções para preenchimento da Comunicação de Acidente do Trabalho - CAT [Internet]. Brasília: Ministério da Previdência Social; 1999 maio [acesso em 2012 nov 23];1:1-22. Disponível em: http://www.mpas.gov.br/arquivos/office/4_101112-101538142.pdf.

7. Vasconcelos SP, Fischer FM, Reis AOA, Moreno CRC. Fatores associados à capacidade para o trabalho e percepção de fadiga entre trabalhadores de enfermagem da Amazônia Ocidental. Rev Bras Epidemiol [Internet]. 2011 [acesso em 2012 out 4]; 14(4):688-97. Disponível em: http://www.scielo.br/scielo.php?pid=S1415790X2011000400015\&script=sci_arttext.

8. Oliveira AC, Diaz MEP, Toledo AD. Acidentes de trabalho com materiais perfurocortantes entre a equipe multiprofissional de uma unidade de emergência. Ciênc Cuid Saúde [Internet]. 2010 abril/jun [acesso em 2012 set 12];9(2):341-49. Disponível em: http://periodicos.uem.br/ojs/index.php/CiencCuidSaude/article/view/8537.

9. Spagnuolo RS, Baldo RCS, Guerrini IA. Análise epidemiológica dos acidentes com material biológico registrados no Centro de Referência em Saúde do Trabalhador Londrina-PR. Rev Bras Epidemiol [Internet]. 2008 [acesso em 2012 set 11];11(2):315-23. Disponível em: http://www.scielo.br/scielo.php?script=sci_arttext\&pid=S1415$790 \times 2008000200013$.

10. Oliveira AC, Paiva MHRS, Paula AO, Gama CS. Acidentes com material biológico entre alunos de graduação em medicina. Ciênc Cuid Saúde [Internet]. 2011 [acesso em 2012 set 14];10(1):89-95. Disponível http://periodicos.uem.br/ojs/index.php/CiencCuidSaude/article/view/9512.

11. Rodriguês VMCP, Ferreira ASS. Fatores geradores de estresse em enfermeiros de Unidades de Terapia Intensiva. Rev Latinoam Enferm [Internet]. 2011 [acesso em 2012 set 2];19(4):1025-32. Disponível em: http://www.scielo.br/pdf/rlae/v19n4/pt_23.pdf. 


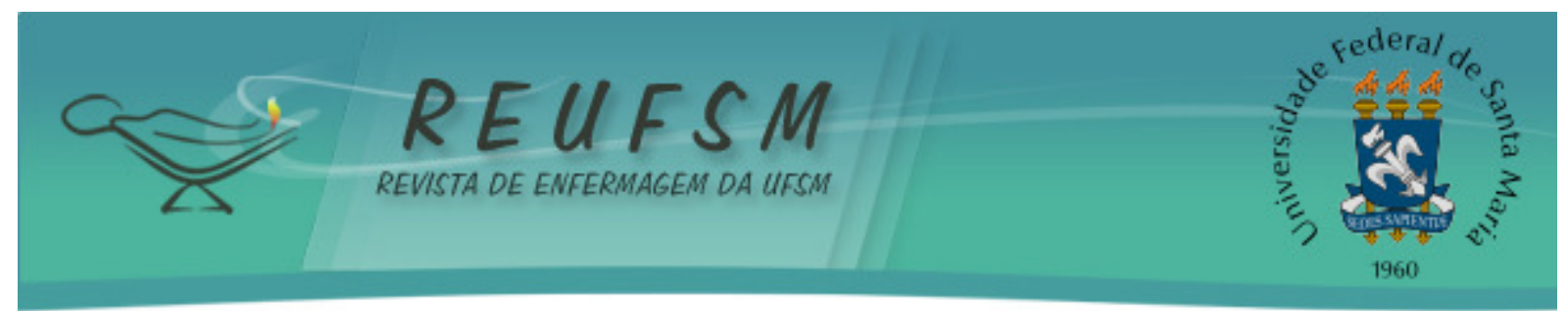

12. Bonini AM, Zeviani CP, Canini SRMS. Exposição ocupacional dos profissionais de enfermagem de uma unidade de terapia intensiva a material biológico. Rev Eletrônica Enferm [Internet]. 2009 [acesso em 2012 set 10];11(3):658-664. Disponível em: http: //www.fen.ufg.br/revista/v11/n3/v11n3a25.htm.

13. Salles CLSS, Silva A. Acidentes de trabalho e o plano de gerenciamento de resíduos de serviço de saúde. Ciênc Cuid Saude [Internet]. 2009 out/dez [acesso em 2012 set 5];8(4):652-9. Disponível em: http://periodicos.uem.br/ojs/index.php/CiencCuidSaude/article/download/9695/5400.

14. Lima LM, Oliveira CC, Rodriguês KMR. Exposição ocupacional por material biológico no Hospital Santa Casa de Pelotas - 2004 a 2008. Esc Anna Nery Rev Enferm [Internet]. 2011 [acesso em 2012 ago 5];15(1):96-102. Disponível em:

http: / / eean.edu.br/audiencia_pdf.asp?aid2=622\&nomeArquivo=v15n1a14_pt.pdf.

15. Brasil. Ministério do Trabalho e Emprego. Legislação. Norma Regulamentadora 9 (NR09). Programas de Prevenção de Riscos Ambientais [Internet]. [acesso em 2012 out 10]. Disponivel em:

http://portal.mte.gov.br/data/files/FF8080812BE914E6012BEF1CA0393B27/nr_09_at.pdf.

16. Rossato EM, Ferreira J. Acidentes com perfurocortantes e cobertura vacinal contra hepatite B entre trabalhadores da Saúde no Município de Santa Rosa, Estado do Rio Grande do Sul, Brasil, 2008. Epidemiol Serv Saúde [Internet]. 2012 [acesso em 2012 nov 10];21(3):487-96. Disponível

em:

http://scielo.iec.pa.gov.br/scielo.php?script=sci_arttext\&pid=S1679-

$49742012000300014 \& \operatorname{lng}=$ pt\&nrm=iso

17. Brasil. Ministério da Saúde. Portaria $n^{\circ} 777$, de 28 de abril de 2004. Dispõe sobre os procedimentos técnicos para a notificação compulsória de agravos à saúde do trabalhador, no Sistema Único de Saúde - SUS [Internet]. 2004 [acesso em 2012 out 19]. Disponível em: http://dtr2001.saude.gov.br/sas/PORTARIAS/Port2004/GM/GM-777.htm.

18. Oliveira AC, Gonçalves JA. Acidente ocupacional por material perfurocortante entre profissionais de saúde de um Centro Cirúrgico. Rev Esc Enferm USP [Internet]. 2010 [acesso em 2012 jul 16];44(2):482-7. Disponível em: http://www.scielo.br/pdf/reeusp/v44n2/34.pdf.

19. Brasil. Ministério da Previdência Social. Saúde e Segurança Ocupacional [Internet]. 2012 [acesso em 2012 ago 2]. Disponível em: http: /www.previdenciasocial.gov.br/conteudoDinamico.php?id=39.

20. Almeida CAF, Benatti MCC. Exposições ocupacionais por fluidos corpóreos entre trabalhadores da saúde e sua adesão à quimioprofilaxia. Rev Esc Enferm USP [Internet]. 2007 [acesso em 2012 set 10];41(1):120-6. Disponível em: http: / /www.scielo.br/pdf/reeusp/v41n1/v41n1a15.pdf.

21. Martins AMEBL, Pereira RD, Ferreira RC. A adesão a protocolo pós-exposição ocupacional de acidentes entre cirurgiões dentistas. Rev Saúde Pública [Internet]. 2010 [acesso em 2012 ago 22];44(3):529-40 .Disponível em: http: //www.scielo.br/pdf/rsp/v44n3/17.pdf.

22. Garcia LP, Blank VLG. Condutas pós-exposição ocupacional a material biológico na odontologia. Rev Saúde Pública [Internet]. 2008 [acesso em 2012 nov 4];42(2):279-86. Disponível em: http://www.scielo.br/pdf/rsp/v42n2/6474.pdf. 


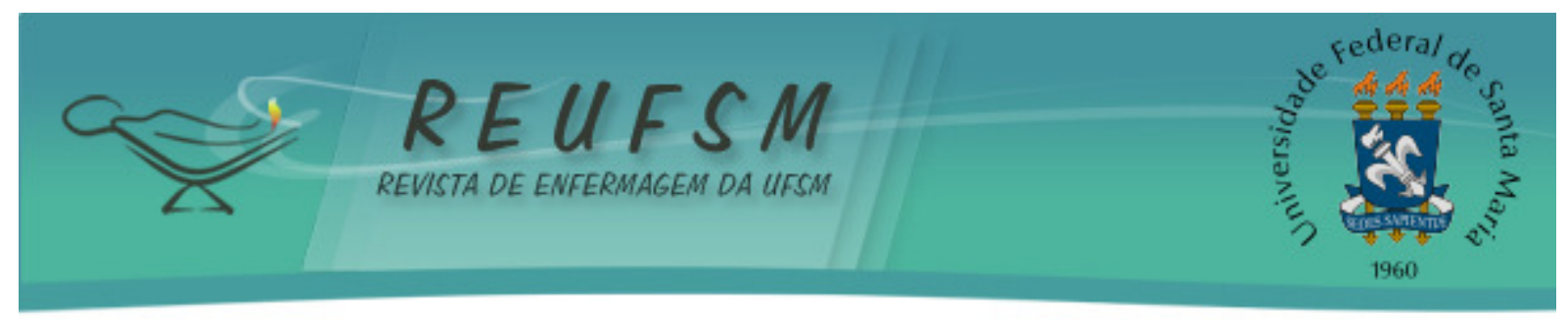

23. Prochnow A, Magnago TSBS, Tavares JP, Beck CLC, Silva RM, Ceron MDS, Castro RR. Acidente de trabalho: uma revisão integrativa. Rev Enferm UFSM [Internet]. 2012 [acesso em 2013 jan 18];2(1):156-64. Disponível em: http://cascavel.ufsm.br/revistas/ojs2.2.2/index. php/reufsm/article/view/2624.

Data de recebimento: $14 / 01 / 2013$

Data de aceite: 12/09/2013

Contato com autor responsável: Tânia Solange Bosi de Souza Magnago

E-mail: tmagnago@terra.com.br

Endereço: Avenida Roraima, 1000 Centro de Ciências da Saúde Prédio 26, Cidade Universitária, Universidade Federal de Santa Maria, RS.

CEP 97105900 